\title{
Características Dendrométricas, Físicas e Químicas da Myracrodruon urundeuva e da Leucaena leucocephala
}

\author{
Lázaro Lavoisier Honorato da Silva ${ }^{1}$, Elisabeth Oliveira $^{1}$, Leandro Calegari ${ }^{1}$, \\ Marllus Carneiro Pimenta ${ }^{1}$, Maysa Kevia Linhares Dantas ${ }^{1}$
}

${ }^{1}$ Programa de Pós-graduação em Ciências Florestais, Universidade Federal de Campina Grande - UFCG, Patos/PB, Brasil.

\begin{abstract}
RESUMO
Com o objetivo de avaliar características dendrométricas, físicas e químicas da Myracrodruon urundeuva e Leucaena leucocephala foi realizada supressão de cinco exemplares de cada espécie. Os parâmetros dendrométricos avaliados foram: DAP, altura, volume. Avaliou-se a densidade básica e foram feitas análises químicas da madeira. O experimento foi arranjado em delineamento inteiramente casualizado (DIC), com valores analisados pelo teste $\mathrm{F}$ ao nível de $5 \%$. As espécies $M$. urundeuva e L. leucocephala apresentaram, respectivamente, média de DAP 10,00 cm; 14,08 cm; altura total $8,20 \mathrm{~m} ; 12,93 \mathrm{~m}$; altura comercial 4,90 m; 10,07 m; volume com casca (C/C) 0,032 $\mathrm{m}^{3} ; 0,104 \mathrm{~m}^{3}$; volume sem casca (S/C) $0,025 \mathrm{~m}^{3} ; 0,095 \mathrm{~m}^{3}$. M. urundeuva apresentou maior densidade básica. O teor de cinzas encontrado para $M$. urundeuva foi superior. Já os teores de extrativos totais e holocelulose da M. urundeuva e da L. leucocephala foram semelhantes. A L. leucocephala obteve maior teor de lignina total e poder calorífico superior. Portanto, as duas espécies apresentaram boas características físicas, químicas e energéticas.
\end{abstract}

Palavras-chave: caatinga, madeira, poder calorífico.

\section{Dendrometric, Physical and Chemical Properties Characteristics of Myracrodruon urundeuva and Leucaena leucocephala}

\begin{abstract}
To evaluate dendrometric characteristics, physical and chemical properties of Myracrodruon urundeuva and Leucaena leucocephala was done suppression of five samples of each species. The dendrometric parameters evaluated were: DAP; height; volume. It was evaluated basic density and chemical analysis of wood were made. The experiment was arranged in a completely randomized design (DIC), with values analyzed by the test "F" at $5 \%$. The species had a mean DAP 10.00; $14.08 \mathrm{~cm}$; overall height $8.20 ; 12.93 \mathrm{~m}$; commercial height 4.90; $10.07 \mathrm{~m}$; volume shelled (C/C) 0.032; $0.104 \mathrm{~m}^{3}$; volume not shelled (S/C) $0.025 ; 0.095 \mathrm{~m}^{3} M$. urundeuva and L. leucocephala, respectively. The M. urundeuva has a higher basic density. The ash content found in $M$. urundeuva was superior. Now, the total extractive content and holocelulose of M. urundeuva and L. leucocephala were similar. The L. leucocephala got higher total lignin content and higher calorific power. Therefore, the two species have good physical, chemical and energy characteristics.
\end{abstract}

Keywords: caatinga, wood, calorific value. 


\section{INTRODUÇÃO}

Exclusivo do Brasil, o bioma Caatinga possui características de regióes semiáridas, como ecossistema bastante rico em flora e fauna e capacidade de adaptação a condições climáticas extremas, ou seja, da seca mais prolongada à possível enchente. Dentre os biomas brasileiros, a Caatinga é o mais negligenciado em seus diferentes aspectos, com o uso inadequado e não sustentável dos solos e recursos naturais, praticados há centenas de anos (Pereira \& Pereira, 2012; Velloso et al., 2002).

A flora da Caatinga representa, para a população inserida nesse bioma, valores de importância ecológica, cultural e econômica, proporcionando às comunidades que vivem em suas proximidades a utilização dos recursos florestais oferecidos para sobreviverem, manterem costumes e gerarem rendas para as famílias, sendo esses recursos de caráter madeireiros (a lenha, o carvão e a estaca para cerca) e/ou de caráter não madeireiro (as folhas e cascas para remédios fitoterápicos, as fibras utilizadas na confecção de artesanato etc.). Algumas espécies podem ser citadas, como: Mimosa tenuiflora, Poincianella pyramidalis, Anadenanthera colubrina, Aspidosperma pyrifolium e Myracrodruon urundeuva.

A hierarquia taxonômica da aroeira (Myracrodruon urundeuva Allemão) é descrita de acordo com o Sistema de Classificação de Cronquist, em que a espécie pertence à divisão Magnoliophyta (Angiosperma), classe Magnoliopsida (Dicotiledônias), ordem Sapindales e família Anacardiaceae. A Myracrodruon urundeuva possui ampla distribuição geográfica no Brasil, ocorrendo ainda em outros países da América do Sul, a exemplo da Argentina, Bolívia e Paraguai. É uma árvore caducifólia, de copa larga, de fuste reto e alto, com crescimento considerado de lento a moderado. A madeira é considerada muito pesada, com densidade aparente variando entre $1,00 \mathrm{~g}$ e $1,21 \mathrm{~g} \cdot \mathrm{cm}^{-3}$ a $15 \%$ de umidade, de difícil trabalhabilidade, alta resistência mecânica e ao apodrecimento ou ataque de cupins de madeira seca. Apresenta várias opções de utilização, como: obras externas, postes, vigas, na carpintaria etc. (Carvalho, 2003; Maia, 2004).

No Brasil, o uso de árvores exóticas ganhou ênfase em vários setores de produtos florestais. A necessidade de gerar maior quantidade de insumo em menor espaço de tempo e reduzir a pressão sobre as matas nativas foram fatores que, combinados, motivaram grandes empresas a investirem no plantio de espécies exóticas. A adaptação às condições climáticas e as características semelhantes às espécies nativas para determinada finalidade são outros fatores que contribuem para o uso das mesmas. A leucena é um exemplo de espécie exótica inserida na Caatinga que já mostrou boa adaptabilidade às condições climáticas.

A leucena [Leucaena leucocephala (Lam.) R. de Wit] é uma espécie arbóreo-arbustiva, pertencente à família Mimosaceae (Leguminosae - Mimosoideae), nativa das Américas. É uma leguminosa com ampla diversidade de uso, por isso tem sido usada como opção de plantio em regiões tropicais. Apresenta bom desenvolvimento em regiões com precipitação entre $600 \mathrm{~mm}$ e $1.700 \mathrm{~mm}$ de chuva por ano, sendo também encontrada em regiões onde o regime de chuva é de $250 \mathrm{~mm}$ anual. Existem diferentes variedades da Leucaena leucocephala, destinadas a diferentes usos, como produção de forragem, adubo verde, enriquecimento e melhoramento do solo, entre outros. O tipo Salvador, por exemplo, tem porte arbóreo, apresenta fuste retilíneo, sendo adequado para a produção de lenha, carvão, celulose e madeira. No Brasil, as variedades da Leucaena leucocephala empregadas apresentam densidade básica da madeira de $0,55-0,70 \mathrm{~g} \cdot \mathrm{cm}^{-3}$. O comportamento silvicultural é destacado nas condições do semiárido nordestino, apresentando densidade da madeira semelhante a outras espécies exóticas e a espécies nativas (Drumond \& Ribaski, 2010; Franco \& Souto, 1986).

A qualidade da madeira é estimada a partir de parâmetros físico-químicos, suas variabilidades e possíveis correlações com outros parâmetros da madeira e do produto final. Um exemplo é a relação proporcional entre a densidade da madeira e sua constituição química, ou seja, os teores de lignina e extrativos (Oliveira et al., 2010). A constituição química e estrutural da madeira influenciará na sua escolha para algumas finalidades, pois certas propriedades organolépticas são determinadas pela presença de substâncias químicas. Partindo da necessidade de conhecer os parâmetros que qualificam a madeira, o presente trabalho teve como objetivo avaliar as características dendrométricas, físicas e químicas da aroeira (Myracrodruon urundeuva Allemão) e da leucena [Leucaena leucocephala (Lam.) R. de Wit]. 


\section{MATERIAL E MÉTODOS}

No presente trabalho, foi realizada a supressão de cinco exemplares das espécies Myracrodruon urundeuva Allemão (aroeira) e Leucaena leucocephala (Lam.) R. de Wit (leucena), seguindo critérios de qualidade fenológica e de sanidade. Os exemplares da Myracrodruon urundeuva foram coletados no Sítio Arapuá, localizado no município de Uiraúna, $\mathrm{PB}$, sob as coordenadas $6^{\circ} 33^{\prime}$ de latitude Sul e $38^{\circ} 25^{\prime}$ de longitude Oeste. A temperatura média anual varia entre $23^{\circ} \mathrm{Ce}$ $30{ }^{\circ} \mathrm{C}$, com o regime pluviométrico baixo e irregular (400 $\mathrm{mm}$ a $600 \mathrm{~mm} / \mathrm{ano}$ ), solo predominante do tipo Podizólico Vermelho-Amarelo, de composição areno-argilosa (Brasil, 2005a). Os exemplares da Leucaena leucocephala foram coletados no Horto Florestal da UFCG, campus de Patos, PB, com coordenadas $7^{\circ} 1^{\prime}$ de latitude Sul e $37^{\circ} 15^{\prime}$ de longitude Oeste. O local apresenta temperatura e precipitação média anual de $28^{\circ} \mathrm{C}$ e $700 \mathrm{~mm}$, respectivamente, e umidade relativa do ar de 55\% (Brasil, 2005b).

Em cada árvore, foram coletados 5 discos $(5 \mathrm{~cm}$ de espessura) de acordo com a Figura 1, a uma altura de 0, zero (base), 25\%, 50\%, 75\% e 100\% da altura comercial do tronco (limite de nível de inclusão, $\varnothing \geq 5 \mathrm{~cm}$ ), sendo medidos os diâmetros com casca e sem casca, nessas posições, para o cálculo do volume de madeira. Antes e depois de cada disco, foram coletados toretes com $15 \mathrm{~cm}$ de espessura. As amostras foram devidamente identificadas e conduzidas ao Laboratório de Energia do Setor de Tecnologia de Produtos Florestais (STPF) da Unidade Acadêmica de Engenharia Florestal (UAEF) da UFCG, no campus de Patos, PB, onde foram realizados os estudos.

Cada disco foi subdividido em quatro partes iguais em forma de cunha, com os cortes passando pela medula, utilizando-se as porções opostas para a determinação da densidade básica. Os toretes foram cavaqueados e homogeneizados por árvore e secos ao ar livre, para serem destinados às análises químicas da madeira.

Os parâmetros dendrométricos foram obtidos a partir da avaliação das características de crescimento: diâmetro à altura do peito (DAP), e altura total e comercial. O volume individual de cada árvore, com casca e sem casca, foi obtido por meio da aplicação sucessiva da fórmula de Smalian $\left(G_{n}\right.$, Equação 1; $\mathrm{V}_{\mathrm{i}}$, Equação 2; e $\mathrm{V}_{\mathrm{T}}$, Equação 3), de acordo com Silva \& Paula (1979).

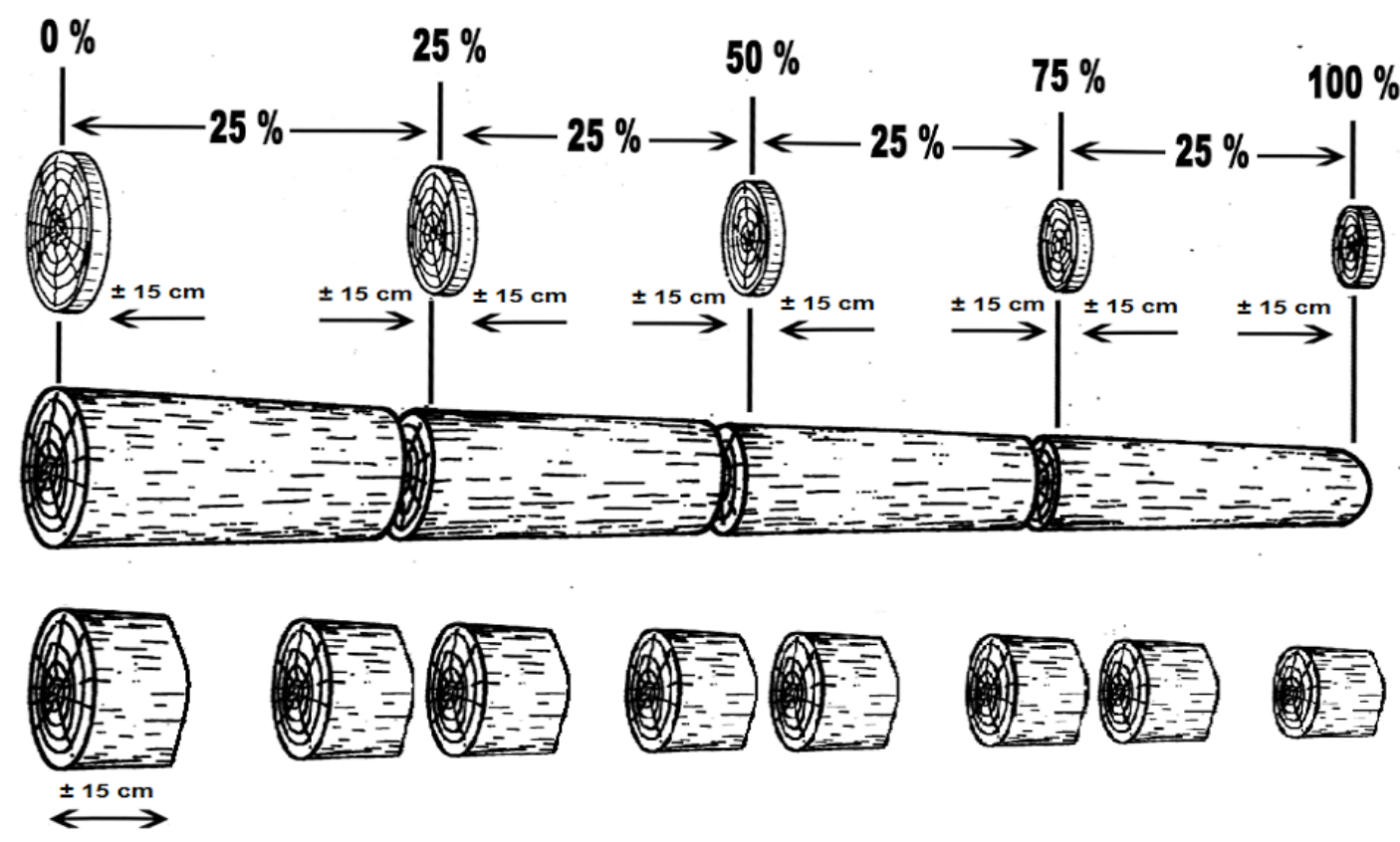

Figura 1. Método utilizado para seccionar discos e toretes da Myracrodruon urundeuva e da Leucaena leucocephala. Fonte: Vital (1984), modificado por Almeida (2010).

Figure 1. Method used for slicing discs and small logs of Myracrodruon urundeuva and Leucaena leucocephala. Source: Vital (1984), modified by Almeida (2010). 
$\mathrm{G}_{\mathrm{n}}=\frac{\pi \cdot \mathrm{D}^{2}}{4}$

$\mathrm{V}_{\mathrm{i}}=\frac{\mathrm{G}_{\mathrm{n}}+\mathrm{G}_{\mathrm{n}+1}}{2} \cdot \mathrm{L}$

$\mathrm{V}_{\mathrm{T}}=\sum \mathrm{V}_{\mathrm{i}}$

em que: $\mathrm{G}_{\mathrm{n}}$ é a área seccionada; $\mathrm{D}$ é o diâmetro da secção; L é o comprimento da tora; $\mathrm{V}_{\mathrm{i}}$ é o volume individual da secção; $\mathrm{V}_{\mathrm{T}}$ é o volume total.

A determinação da densidade básica da madeira foi realizada de acordo com o método para discos utilizando balança hidrostática ( $\mathrm{d}_{\mathrm{b}}$, Equação 4), conforme a NBR-11941 (ABNT, 2003).

$\mathrm{d}_{\mathrm{b}}=\frac{\mathrm{m}_{3}}{\left(\mathrm{~m}_{2}-\mathrm{m}_{1}\right)}$

em que: $\mathrm{d}_{\mathrm{b}}$ é a densidade básica da madeira, em gramas por centímetro cúbico $\left(\mathrm{g} / \mathrm{cm}^{3}\right) ; \mathrm{m}_{3}$ é a massa da amostra seca em estufa a $105^{\circ} \mathrm{C}+2{ }^{\circ} \mathrm{C}$, em gramas (g); $\mathrm{m}_{2}$ é massa do recipiente com água e disco imerso, em gramas (g); $\mathrm{m}_{1}$ é a massa do recipiente com água, em gramas.

A partir dos resultados da densidade básica da madeira foram calculadas a densidade básica média aritmética, DBर̄ A (Equação 5), e a densidade básica média ponderada de cada árvore, DBर̄P (Equação 6).

$\mathrm{DB} \overline{\mathrm{x}} \mathrm{A}=\frac{\mathrm{DB}_{0 \%}+\mathrm{DB}_{25 \%}+\mathrm{DB}_{50 \%}+\mathrm{DB}_{75 \%}+\mathrm{DB}_{100 \%}}{5}$

em que: é a densidade básica média aritmética da árvore $\left(\mathrm{g} / \mathrm{cm}^{3}\right)$; DB é a densidade básica média por ponto de amostragem $\left(\mathrm{g} / \mathrm{cm}^{3}\right)$;

$\mathrm{DB} \overline{\mathrm{x}} \mathrm{P}=\frac{\left(\mathrm{DB} \overline{\mathrm{x}}_{(0-25 \%)} \cdot \mathrm{V}_{(0-25 \%)}\right)+\ldots+\left(\mathrm{DB} \overline{\mathrm{x}}_{(75-100 \%)} \cdot \mathrm{V}_{(75-100 \%)}\right)}{\mathrm{V}_{(0-25 \%)}+\mathrm{V}_{(25-50 \%)}+\mathrm{V}_{(50-75 \%)}+\mathrm{V}_{(75-100 \%)}}(6)$

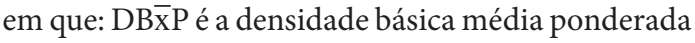
da árvore $\left(\mathrm{g} / \mathrm{cm}^{3}\right) ; \mathrm{DB} \overline{\mathrm{x}}$ é a densidade básica média entre as posições 0-25\%, 25-50\%, 50-75\% e 75-100\% da altura comercial $\left(\mathrm{g} / \mathrm{cm}^{3}\right)$; V é o volume das seções entre as posições 0-25\%, 25-50\%, 50-75\% e 75-100\% da altura comercial $\left(\mathrm{m}^{3}\right)$.

A preparação da madeira para análise química seguiu a norma T 257 om-92 (TAPPI, 1992a), transformando os cavacos em serragem, com auxílio de um moinho tipo Wiley, e classificando-os em peneiras de 40/60 mesh. A análise química foi realizada em duplicata sob uma fração da serragem classificada. O teor absolutamente seco foi determinado em duplicata a partir da norma T 264 om-88 (TAPPI, 1992b). Foram feitas determinações quantitativas de extrativos totais, de lignina, teor de cinzas e holocelulose (obtida por diferença).

Seguindo-se a norma M-3/69 (BRACELPA, 1974a), na determinação de extrativos totais, foi realizada a solubilidade da madeira em álcool/tolueno, álcool e água quente, substituindo o benzeno por tolueno em extratores tipo Soxhlet. Para se terminar o conteúdo de lignina, foi empregado o método Klason, modificado por Gomide \& Demuner (1986). Foi feita uma leitura em espectrofotômetro do filtrado remanescente da análise de lignina, com a finalidade de determinar a lignina solúvel em ácido, de acordo com Goldschimidt (1971). $\mathrm{O}$ teor de lignina total corresponde à soma da lignina residual e da lignina solúvel em ácido. De acordo com a norma M-11/77 (BRACELPA, 1974b), foi verificado o teor de cinzas da madeira. O poder calorífico superior da madeira foi determinado por meio de calorímetro adiabático de acordo com a NBR-8633 (ABNT, 1984).

$\mathrm{O}$ experimento foi arranjado em delineamento inteiramente casualizado (DIC), composto por 2 tratamentos (espécies) e 5 repetições (árvores). Os valores foram submetidos à análise de variância pelo teste $\mathrm{F}$ ao nível de $5 \%$ de probabilidade, com o auxílio do Programa Estatístico ASSISTAT (Silva \& Azevedo, 2013).

\section{RESULTADOS}

As características dendrométricas observadas apresentaram valores médios para diâmetro à altura do peito (DAP) maior na Leucaena leucocephala, menor na Myracrodruon urundeuva. A altura total e comercial foi superior na Leucaena leucocephala em relação à Myracrodruon urundeuva. Da mesma forma, o volume médio com casca e sem casca observado foi maior para Leucaena leucocephala (Tabela 1).

Para a média aritmética e a média ponderada dos valores da densidade básica da madeira, foram observadas diferenças significativas entre as duas espécies (Tabela 1). A Myracrodruon urundeuva apresentou densidade básica média de aproximadamente $740,99 \mathrm{~kg} / \mathrm{m}^{3}$, valor superior à média da Leucaena leucocephala, que foi de $601,96 \mathrm{~kg} / \mathrm{m}^{3}$. Mesmo quando ponderado, o valor médio da densidade básica da Myracrodruon urundeuva $\left(755,75 \mathrm{~kg} / \mathrm{m}^{3}\right)$ também foi superior ao encontrado para Leucaena leucocephala $\left(610,23 \mathrm{~kg} / \mathrm{m}^{3}\right)$. 
A madeira da Myracrodruon urundeuva apresentou maior quantidade de cinzas em sua constituição, sendo composta, em média, por 1,08\% de materiais inorgânicos, enquanto a Leucaena leucocephala rendeu apenas 0,66\% do mesmo material (Tabela 2). Da mesma forma, a quantidade de materiais orgânicos, ou seja, de extrativos que foram isolados, apresentou superioridade significativa para a Myracrodruon urundeuva (12,75\%)

Tabela 1. Valores médios dascaracterísticas dendrométricasedensidadebásica da madeiradaMyracrodruonurundeuva e da Leucaena leucocephala.

Table 1. Average values for dendrometric characteristics and basic wood density of Myracrodruon urundeuva and Leucaena leucocephala.

\begin{tabular}{|c|c|c|c|c|c|c|c|c|}
\hline Espécie & ÁRV. & $\begin{array}{l}\text { DAP } \\
(\mathrm{cm})\end{array}$ & $\begin{array}{l}\text { ALT. T. } \\
(\mathrm{m})\end{array}$ & $\begin{array}{l}\text { ALT. C. } \\
(\mathbf{m})\end{array}$ & $\begin{array}{c}\text { VOL. } \\
\text { C/C } \\
\left(\mathrm{m}^{3}\right)\end{array}$ & $\begin{array}{c}\text { VOL. } \\
\text { S/C } \\
\left(\mathrm{m}^{3}\right)\end{array}$ & $\begin{array}{c}\mathrm{DB} \overline{\mathbf{x}} \mathrm{A} \\
\left(\mathrm{kg} / \mathrm{m}^{3}\right)\end{array}$ & $\begin{array}{c}\mathrm{DB} \bar{x} P \\
\left(\mathrm{~kg} / \mathrm{m}^{3}\right)\end{array}$ \\
\hline \multirow{5}{*}{$\begin{array}{l}\text { Myracrodruon } \\
\text { urundeuva }\end{array}$} & 1 & 12,10 & 8,00 & 5,00 & 0,041 & 0,034 & 737,64 & 749,18 \\
\hline & 2 & 8,76 & 7,50 & 3,90 & 0,022 & 0,018 & 704,49 & 710,99 \\
\hline & 3 & 9,39 & 8,00 & 5,20 & 0,030 & 0,023 & 687,92 & 705,24 \\
\hline & 4 & 10,19 & 9,50 & 5,20 & 0,034 & 0,027 & 779,70 & 797,73 \\
\hline & 5 & 9,55 & 8,00 & 5,20 & 0,030 & 0,025 & 795,17 & 815,67 \\
\hline Médias & --- & 10,00 & 8,20 & 4,90 & 0,032 & 0,025 & $740,99 a$ & $755,75 a$ \\
\hline \multirow{5}{*}{$\begin{array}{l}\text { Leucaena } \\
\text { leucocephala }\end{array}$} & 1 & 13,54 & 10,60 & 7,90 & 0,079 & 0,068 & 613,52 & 621,95 \\
\hline & 2 & 13,22 & 13,15 & 10,55 & 0,088 & 0,080 & 602,32 & 609,78 \\
\hline & 3 & 12,42 & 12,70 & 9,20 & 0,080 & 0,073 & 603,28 & 605,80 \\
\hline & 4 & 14,81 & 14,00 & 12,00 & 0,127 & 0,119 & 586,46 & 596,51 \\
\hline & 5 & 16,40 & 14,20 & 10,70 & 0,147 & 0,133 & 604,21 & 617,09 \\
\hline Médias & --- & 14,08 & 12,93 & 10,07 & 0,104 & 0,095 & $601,96 b$ & $610,23 b$ \\
\hline QMRes & --- & --- & --- & --- & --- & --- & $1.121,831$ & $1.292,887$ \\
\hline CV(\%) & & --- & --- & --- & --- & --- & 4,99 & 5,96 \\
\hline
\end{tabular}

$\mathrm{DAP}=$ diâmetro à altura do peito; ALT. T. $=$ altura total; ALT. C. $=$ altura comercial; VOL. C/C = volume com casca; VOL. S/C = volume sem casca; $\mathrm{DB} \overline{\mathrm{x}} \mathrm{A}$ = densidade básica média aritmética; $\mathrm{DB} \overline{\mathrm{x}} \mathrm{A}$ = densidade básica média ponderada; QMRes = quadrado médio do resíduo; $\mathrm{CV}$ = coeficiente de variação; Médias seguidas pela mesma letra na coluna não diferem entre si pelo teste $\mathrm{F}$ ao nível de $5 \%$.

Tabela 2. Valores médios das análises químicas e poder calorífico da madeira da Myracrodruon urundeuva e da Leucaena leucocephala.

Table 2. Average values of chemical analyzes and calorific value of Myracrodruon urundeuva and Leucaena leucocephala wood.

\begin{tabular}{|c|c|c|c|c|c|c|}
\hline Espécie & Árvore & $\begin{array}{c}\text { CINZ. M. } \\
(\%)\end{array}$ & $\begin{array}{c}\text { EXTR. T. } \\
(\%)\end{array}$ & $\begin{array}{c}\text { LIG. T. } \\
(\%)\end{array}$ & $\begin{array}{l}\text { HOL. } \\
(\%)\end{array}$ & $\begin{array}{c}\text { PCSM } \\
\text { (kcal/kg) }\end{array}$ \\
\hline \multirow{5}{*}{$\begin{array}{l}\text { Myracrodruon } \\
\text { urundeuva }\end{array}$} & 1 & 1,50 & 14,75 & 26,25 & 57,50 & $4.568,219$ \\
\hline & 2 & 1,20 & 11,00 & 29,28 & 58,52 & $4.840,646$ \\
\hline & 3 & 0,80 & 11,50 & 25,89 & 61,81 & $4.871,964$ \\
\hline & 4 & 1,30 & 12,25 & 26,92 & 59,53 & $4.522,052$ \\
\hline & 5 & 0,60 & 14,25 & 27,32 & 57,83 & $4.495,282$ \\
\hline Médias & --- & $1,08 \mathrm{a}$ & $12,75 a$ & $27,13 b$ & $59,04 a$ & $4.659,633 b$ \\
\hline \multirow{5}{*}{$\begin{array}{l}\text { Leucaena } \\
\text { leucocephala }\end{array}$} & 1 & 0,80 & 12,5 & 29,11 & 57,59 & $4.946,214$ \\
\hline & 2 & 0,80 & 11,25 & 29,48 & 58,47 & $4.932,506$ \\
\hline & 3 & 0,60 & 10,25 & 29,40 & 59,75 & $5.107,167$ \\
\hline & 4 & 0,50 & 10,00 & 29,34 & 60,16 & $5.083,091$ \\
\hline & 5 & 0,60 & 10,00 & 29,20 & 60,20 & $4.914,973$ \\
\hline Médias & --- & $0,66 b$ & $10,80 \mathrm{a}$ & $29,31 \mathrm{a}$ & $59,23 a$ & $4.996,790 \mathrm{a}$ \\
\hline QMRes & --- & 0,078 & 1,975 & 0,888 & 2,170 & $20.645,224$ \\
\hline CV(\%) & --- & 32,00 & 11,94 & 3,34 & 2,49 & 2,98 \\
\hline
\end{tabular}

CIZ. M. = cinzas da madeira; EXTR. T. = extrativo total; LIG. T. = lignina total; HOL. = holocelulose; PCSM = poder calorífico superior da madeira; $\mathrm{QMRes}=$ quadrado médio do resíduo; $\mathrm{CV}$ = coeficiente de variação; Médias seguidas pela mesma letra na coluna não diferem entre si pelo teste $\mathrm{F}$ ao nível de $5 \%$. 
em relação à Leucaena leucocephala (10,80\%). Os teores de lignina encontrados nas espécies em estudo também se mostraram divergentes, com menor teor para Myracrodruon urundeuva $(27,13 \%)$ e maior teor para a Leucaena leucocephala $(29,31 \%)$. Já o teor de holocelulose encontrado na madeira das referidas espécies foi semelhante. A análise de energia bruta realizada para determinar o poder calorífico superior da madeira resultou num rendimento energético maior para a Leucaena leucocephala, com 4.996,790 kcal/kg, sendo que a Myracrodruon urundeuva rendeu 4.659,633 $\mathrm{kcal} / \mathrm{kg}$.

\section{DISCUSSÃO}

A densidade da madeira é influenciada pelo ajuste de diversos fatores anatômicos, o que a torna uma caraterística complexa, porém importante para as propriedades físicas e mecânicas, podendo variar entre espécies distintas, na mesma espécie ou em diferentes regiões da mesma árvore (Foelkel et al., 1971).

Os valores da densidade básica média aritmética das duas espécies foram inferiores aos encontrados por Medeiros et al. (2012), que, estudando duas espécies da Caatinga, encontraram densidade de $1.052,46 \mathrm{~kg} / \mathrm{m}^{3}$, para Poincianella pyramidalis, e $997,75 \mathrm{~kg} / \mathrm{m}^{3}$ para Handroanthus impertiginosus. Vários fatores podem ter influenciado para as espécies em estudo terem apresentado médias inferiores, como idade, tipo de solo e condições ambientais. Batista et al. (2010), ao pesquisarem clones de três espécies de Eucalyptus, observaram densidade de $460,00 \mathrm{~kg} / \mathrm{m}^{3}$ para Eucalyptus saligna; $450,00 \mathrm{~kg} / \mathrm{m}^{3}$ para Eucalyptus grandis e $560,00 \mathrm{~kg} / \mathrm{m}^{3}$ para Eucalyptus dunni, valores estes inferiores ao encontrado para a Leucaena leucocephala $\left(602,00 \mathrm{~kg} / \mathrm{m}^{3}\right)$, que, da mesma forma, é uma espécie exótica. A densidade é muito variável em espécies comerciais, devido às condições climáticas, seu teor de umidade e infiltrações no cerne (Martins \& Vieira, 2004).

O teor de lignina foi de $27,13 \%$ e $29,31 \%$ para Myracrodruon urundeuva e Leucaena leucocephala, respectivamente, sendo superiores ao encontrado para Poincianella pyramidalis $(26,64 \%)$, ao passo que a quantidade de cinza presente na madeira da Myracrodruon urundeuva $(1,08 \%)$ e da Leucaena leucocephala $(0,66 \%)$ foi inferior à quantidade de cinza presente na madeira da Poincianella pyramidalis $(3,69 \%)$ (Medeiros et al., 2012). A menor quantidade de cinzas indica que menos resíduos serão gerados após a queima da madeira, favorecendo a limpeza do ambiente onde está sendo utilizada a madeira. As cinzas também não são desejadas no setor de siderurgia porque alguns dos minerais presentes na madeira são prejudiciais aos processos de produção. A composição e o teor das cinzas estão diretamente relacionados com a disponibilidade de minerais presentes no solo (Oliveira, 2003).

Ao observar os valores encontrados para o teor de extrativos totais presentes na madeira da Myracrodruon urundeuva (12,75\%) e da Leucaena leucocephala (10,80\%), constatou-se superioridade das duas espécies aos valores encontrados para mesma variável por Vale et al. (2010), quando estudaram as propriedades químicas da madeira de cinco espécies do Cerrado, em que as médias variaram entre $6,14 \%$ e $8,54 \%$ de extrativos. Já Fonsêca (2011), ao realizar um estudo comparativo entre o Ziziphus joazeiro e Prosopis juliflora, no semiárido paraibano, obteve maiores valores de extrativos totais, com 22,69\% para a primeira e 29,25\% para a segunda.

O poder calorífico encontrado para a Leucaena leucocephala $(4.996,79 \mathrm{kcal} / \mathrm{kg})$, que é uma espécie exótica, mostrou-se superior à espécie nativa estudada, a Myracrodruon urundeuva $(4.659,633 \mathrm{kcal} / \mathrm{kg})$, bem como às espécies estudadas por Santos et al. (2013), que foram oriundas de um plano de manejo florestal no Estado do Rio Grande do Norte, em que, dentre todas as espécies, a que se destacou foi a Mimosa tenuiflora, com $4.823 \mathrm{kcal} / \mathrm{kg}$. Medeiros et al. (2012) também encontraram valores inferiores para a Poincianella pyramidalis e a Handroanthus impertiginosus, ambas da região semiárida, com 4.413,50 kcal e 4.806,30 kcal/kg, respectivamente.

\section{CONCLUSÕES}

A madeira da Myracrodruon urundeuva mostrou-se de boa qualidade em suas propriedades físicas, químicas e energéticas, porém seu uso deve ser restrito e sob forma de manejo, já que a mesma é uma espécie que está em extinção. Da mesma forma, a madeira da Leucaena leucocephala apresentou boa qualidade nas propriedades estudadas, podendo ser usada sem restrições de exploração, uma vez que é uma espécie exótica e com excelente adaptabilidade às condições semiáridas. 


\section{STATUS DA SUBMISSÃO}

Recebido: 7 jul., 2016

Aceito: 1 out., 2016

\section{AUTOR(ES) PARA CORRESPONDÊNCIA}

\section{Lázaro Lavoisier Honorato da Silva, Elisabeth Oliveira}

Avenida Universitária, s/n, Bairro Santa Cecília, CP 61, CEP 58708-110, Patos, PB, Brasil

e-mails: lazarolavoisier@bol.com.br,

betholiveira12@gmail.com

\section{REFERÊNCIAS}

Almeida AMC. Avaliação anatômica, físico-química e energética da madeira das espécies Piptadenia stipulacea (Benth.) Ducke e Amburana cearensis (Allemão) A. C. Smith de ocorrência no semiárido nordestino brasileiro [dissertação]. Patos: Programa de Pós-graduação em Ciências Florestais, Universidade Federal de Campina Grande; 2010.

Associação Brasileira de Celulose e Papel - BRACELPA. M-3/69: preparação de madeira livre de extrativos. São Paulo; 1974a.

Associação Brasileira de Celulose e Papel - BRACELPA. M-11/77: teor de cinzas ou minerais. São Paulo; 1974b.

Associação Brasileira de Normas Técnicas - ABNT. NBR8633: carvão vegetal: determinação do poder calorífico. São Paulo; 1984.

Associação Brasileira de Normas Técnicas - ABNT. NBR-11941: madeira: determinação da densidade básica. São Paulo; 2003.

Batista DC, Klitzke RJ, Santos CVT. Densidade básica e retratibilidade da madeira de clones de três espécies de Eucalyptus. Ciência Florestal 2010; 20(4): 665-674. http://dx.doi.org/10.5902/198050982425.

Brasil. Ministério de Minas e Energia. Projeto cadastro de fontes de abastecimento por água subterrânea: diagnóstico do município de Uiraúna, estado da Paraíba. Recife; 2005a.

Brasil. Ministério de Minas e Energia. Projeto cadastro de fontes de abastecimento por água subterrânea: diagnóstico do município de Patos, estado da Paraíba. Recife; 2005b.

Carvalho PER. Espécies arbóreas brasileiras. Brasília: Embrapa Informação Tecnológica; Colombo: Embrapa Florestas; 2003.

Drumond MA, Ribaski J. Leucena (Leucaena leucocephala): leguminosa de uso múltiplo para o semiárido brasileiro. Comunicado Técnico. Embrapa Semiárido 2010; 142: 1-8.
Foelkel CEB, Brasil MAM, Barrichelo LEG. Métodos para determinação da densidade básica de cavacos para coníferas e folhosas. Instituto de Pesquisas e Estudos Florestais 1971; 2/3: 65-74.

Fonsêca CMB. Estudo comparativo do potencial energético do Juazeiro (Ziziphus joazeiro Martius) e da Algarobeira (Prosopis juliflora (Sw.) DC.) na produção de carvão no semiárido paraibano [dissertação]. Patos: Programa de Pós-graduação em Ciências Florestais, Universidade Federal de Campina Grande; 2011.

Franco AA, Souto SM. Leucaena leucocephala: uma leguminosa com múltiplas utilidades para os trópicos. Comunicado Técnico 1986; 2: 1-7.

Goldschimidt O. Ultraviolet spectra. In: Sarkanen $\mathrm{KV}$, Ludwwig CH, editors. Lignins. New York: Wiley Interscience; 1971. p. 241-266.

Gomide JL, Demuner BJ. Determinação do teor de lignina em material lenhoso: método Klason modificado. O Papel 1986; 47(8): 36-38.

Maia GN. Caatinga: árvores e arbustos e suas utilidades. São Paulo: D\&Z; 2004.

Martins JG, Vieira A. Materiais de construção: derivados de madeira. 2004

Medeiros PN No, Oliveira E, Calegari L, Almeida AMC, Pimenta AS, Carneiro ACO. Características físico-químicas e energéticas de duas espécies de ocorrência no semiárido brasileiro. Ciência Florestal 2012; 22(3): 579-588.

Oliveira AC, Carneiro ACO, Vital BR, Almeida W, Pereira BLC, Cardoso MT. Parâmetros de qualidade da madeira e do carvão vegetal de Eucalyptus pellita F. Muell. Scientia Forestalis 2010; 38(87): 431-439.

Oliveira E. Características anatômicas, químicas e térmicas da madeira de três espécies de maior ocorrência no semiárido nordestino [tese]. Viçosa: Universidade Federal de Viçosa; 2003.

Pereira DD, Pereira FC. Curso de capacitação em manejo ambiental integrado: Ecologia das caatingas. Patos: SOS Sertão; 2012

Santos RC, Carneiro ACO, Pimenta AS, Castro RVO, Marinho IV, Trugilho PF et al. Potencial energético da madeira de espécies oriundas de plano de manejo florestal no Estado do Rio Grande do Norte. Ciência Florestal 2013; 23(2): 491-502. http://dx.doi.org/10.5902/198050989293.

Silva FAZ, Azevedo CAV. Principal components analysis in the software assistat-statistical attendance. In: Proceedings of the 7th World Congress on Computers in Agriculture; 2013; Reno. Reno: American Society of Agricultural and Biological Engineers; 2013.

Silva JAA, Paula F No. Princípios básicos de dendrometria. Recife: Universidade Federal Rural de Pernambuco; 1979. 
Technical Association of the Pulp and Paper Industry - TAPPI. T-257 om- 92: sampling and preparing wood for analysis. Atlanta; 1992a.

Technical Association of the Pulp and Paper Industry TAPPI. T-264 om-88: preparation of wood for chemical analysis. Atlanta; $1992 \mathrm{~b}$.
Vale AT, Dias IS, Santana MAE. Relações entre propriedades químicas, físicas e energéticas da madeira de cinco espécies de Cerrado. Ciência Florestal 2010; 20(1): 137 145. http://dx.doi.org/10.5902/198050981767.

Velloso AL, Sampaio EVSB, Sampaio FGC. Ecorregiões propostas para o Bioma Caatinga. São Paulo: The Nature Conservancy; 2002. 